ARTICLE

Received 31 Jul 2013 | Accepted 6 Jan 2014 | Published 11 Feb $2014 \quad$ DOl: 10.1038/ncomms4196

\title{
Regional climate model simulations indicate limited climatic impacts by operational and planned European wind farms
}

Robert Vautard ${ }^{1}$, Françoise Thais², Isabelle Tobin ${ }^{1}$, François-Marie Bréon', Jean-Guy Devezeaux de Lavergne², Augustin Colette ${ }^{3}$, Pascal Yiou ${ }^{1} \&$ Paolo Michele Ruti ${ }^{4}$

The rapid development of wind energy has raised concerns about environmental impacts. Temperature changes are found in the vicinity of wind farms and previous simulations have suggested that large-scale wind farms could alter regional climate. However, assessments of the effects of realistic wind power development scenarios at the scale of a continent are missing. Here we simulate the impacts of current and near-future wind energy production according to European Union energy and climate policies. We use a regional climate model describing the interactions between turbines and the atmosphere, and find limited impacts. A statistically significant signal is only found in winter, with changes within $\pm 0.3^{\circ} \mathrm{C}$ and within $0-5 \%$ for precipitation. It results from the combination of local wind farm effects and changes due to a weak, but robust, anticyclonic-induced circulation over Europe. However, the impacts remain much weaker than the natural climate interannual variability and changes expected from greenhouse gas emissions.

\footnotetext{
${ }^{1}$ Laboratoire des Sciences du Climat et de l'Environnement, IPSL, laboratoire CEA-CNRS-UVSQ Orme des Merisiers, 91191 Gif sur Yvette Cedex, France.

${ }^{2}$ I-Tésé, Institut de Technico-Economie des Systèmes Energétiques CEA/DEN/DANS Centre de Saclay Batiment 125 F-91191 Gif sur Yvette Cedex, France. ${ }^{3}$ Institut National de I'Environnement industriel et de RISques, Parc Technologique Alata, BP2, Verneuil-en-Halatte 60550, France. ${ }^{4}$ ENEA Italian National Agency for New Technologies, Energy and Sustainable Economic Development; UTMEA-CLIM Energy Environment Modeling Unit-Climate \& Impact Modeling Laboratory, via Anguillarese 301, I-00123 Roma, Italy. Correspondence and requests for materials should be addressed to R.V. (email: robert.vautard@lsce.ipsl.fr).
} 
O ver the past ten years the worldwide wind power installed capacity has increased by an order of magnitude, reaching about $280 \mathrm{GW}$ in 2012 (ref. 1). Europe has the largest continental capacity ( $>100 \mathrm{GW})$, together with Asia, and has the highest density of wind farms. Wind energy growth is $\sim 10 \%$ per year, with important variations from one country to another. However, wind energy development faces several concerns. First, it is highly sensitive to weather and production is variable. It is potentially sensitive to climate change ${ }^{2-4}$. Then a challenge, which largely remains to be investigated, is to assess the effects of wind farms on climate and environment, especially in regions with intense wind power development.

The most direct atmospheric effect of wind turbines is an additional drag and the generation of wake turbulence. This induces a reduction of the daily temperature range, with daytime cooling and night-time warming ${ }^{5}$, due to increased mixing near the surface. In areas densely covered by wind farms, a net warming was found, reaching $\sim 0.7^{\circ} \mathrm{C}$ over a decade, as detected by remote-sensing observations ${ }^{6-8}$, and similar results are obtained in mesoscale model simulations ${ }^{9,10}$. Wind-tunnel experiments suggested that the energy budget may be modified in the wake of wind farms ${ }^{11}$. In fact, the whole structure of the planetary boundary layer is affected by turbine wake turbulence, and the flow is locally modified near wind farms $s^{8,12,13}$ even potentially altering the wind power resource can be affected when the extracted power density exceeds $1 \mathrm{Wm}^{-2}$ (refs 14,15).

Previous simulations suggested that massive deployment of wind energy in large-scale farms could modify short-term weather in such a way that a 5-day forecast would be significantly altered several thousands of kilometres downstream ${ }^{16}$. Moreover, previous modelling investigations suggested that hypothetical gigantic wind farms, installed over one or several continents, would modify the regional climate and mean atmospheric circulation $^{17-19}$, with temperature changes reaching $\sim 1^{\circ} \mathrm{C}$ and regional precipitation changes exceeding 10\% (ref. 19). These modelling studies have used idealized wind energy development scenarios and, for most of them, a crude representation of the effects of wind turbines.

Here we evaluate for the first time the effects of the current and a realistic scenario of future European wind farms fleet on regional climate. We use a model including a formulation of wind farm effects that account for the elevated nature of drag ${ }^{12,20}$. The effect of turbines on weather is represented by the extraction of momentum and generation of additional turbulent kinetic energy (TKE) in each model layer crossed by the turbine blades. Additional TKE is calculated as the difference between the energy extracted from the flow and the electrical power produced ${ }^{11}$. It avoids the overestimation of local temperature changes such as that found using a roughness-based approach ${ }^{18}$. This parameterization is implemented in the Weather Research and Forecast (WRF) model ${ }^{21,22}$ (see Methods for more details and information on the WRF model configuration used here).

\section{Results}

Wind energy development scenario. The impact of wind energy production on European climate is simulated by representing each of the individual wind farms installed at the end of year 2012, using a global database of installed wind farms ${ }^{1}$, and a scenario of projected installations following European policies for 2020 (ref. 23). The simulations use the turbine characteristics of each wind farm when available (nominal power, hub height and rotor diameter) from this database, and typical power and thrust coefficient formulations (see Methods section and Fig. 1 for details).
The 2020 scenario assumes wind energy production from onshore and offshore farms following the European Energy and Climate Package policy (see Methods section and Supplementary Table 1). It takes into account the concrete objectives in terms of capacities for onshore and offshore energy decided by every member state. To provide location of future wind farms, we used different procedures for onshore and offshore production. For the sake of simplicity, we assume that onshore projected farms will be installed in areas where mean surface wind is maximal in each country, as simulated by a 33-year control simulation without inclusion of wind farms. We use a database of offshore projects ${ }^{1}$ providing indicative locations and installed power. However, in this data the capacity generally exceeded the European Union policy; hence, site locations with maximal mean surface wind were selected as above.

The spatial distribution of installed power for the current and future scenarios is represented in Fig. 1. At present, high-density onshore capacity is mostly over Northern Germany, Denmark, Spain and Italy. In the 2020 scenario case, a substantial development of offshore capacity takes place (additional $\sim 50 \mathrm{GW})$ in the North and Baltic seas, British channel and at a few locations along the Atlantic coast.

Model experiments and evaluation. To evaluate the effects of turbines in each case, 33-year long twin simulations were carried out over the model domain represented in Fig. 1, which corresponds to the EURO-CORDEX regional modelling experiment domain $^{24,25}$. Table 1 summarizes all experiments done. The low resolution of EURO-CORDEX ( $50 \mathrm{~km}: 0.44^{\circ}$ on rotated grid) was used. The first simulation (control (CTL)) assumes no wind turbine. The second simulation (current (CUR)) uses the fleet in operation at the end of $2012(101 \mathrm{GW})$, the third simulation (scenario (SCEN)) uses the fleet as assumed in the 2020 scenario $(220 \mathrm{GW})$

The ability of the model to simulate wind and energy production was first evaluated over the full year of 2012 using a set of 3-hourly surface wind measurements (see Methods section) and hourly wind energy production data as given by electricity grid operators in six countries. The mean surface wind speed is overestimated, with an average factor of $\sim 20 \%$ in areas densely covered by wind farms (see evaluation in Methods section). This wind speed bias of the WRF model was reported in several studies and attributed to the lack of drag induced by subgrid-scale orography ${ }^{26,27}$. The bias is likely to be not due to misrepresentation of the synoptic flow, because a simulation where winds are nudged $^{28}$ to the ERA-Interim re-analyses above $2,500 \mathrm{~m}$ generates similar biases (see Supplementary Figs 1-3).

For this nudged simulation, the model properly reproduces the hourly country mean production (the time correlation $r$ lies between 0.86 and 0.92 , depending on the country) variability of electricity production (see Supplementary Figs 4 and 5), with, however, a significant overestimation (see Supplementary Table 2). This can be explained partly by the wind bias, but also by several other factors limiting the energy provided by the wind farm turbines not considered here, such as turbulence and upwind turbine wake effects inhibiting optimal functioning ${ }^{29}$, turbine maintenance, or subnominal functioning of blades due to dirt, icing and electric losses. For non-nudged simulations, correlation is poorer $(0.15<r<0.73)$ due to chaotic processes that generate synoptic flow excursions away from the re-analyses.

Climate impact of wind energy development. The net impact of the wind turbine fleet on the mean surface temperature for the 2020 scenario is estimated from the differences in long-term averages between the SCEN and CTL simulations. In winter, 

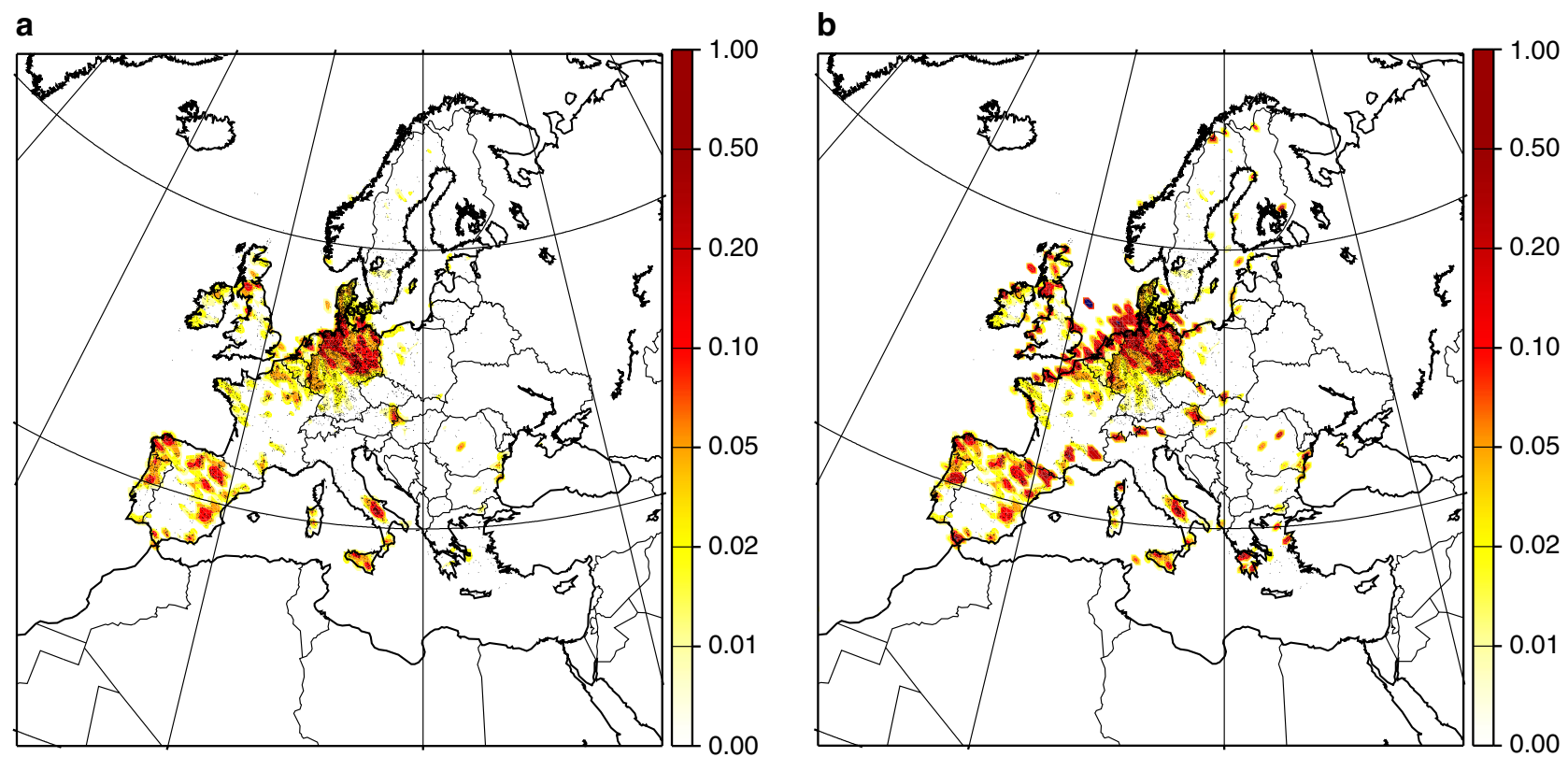

Figure 1 | Installed power for 2012 and 2020. Modelling domain, together with the location of turbines (dots) and distribution of total installed power per grid cell for 2012 (a) and 2020 (b). Units: $\mathrm{MW} \mathrm{km}^{-2}$.

Table 1 | Summary of simulations characteristics.

\begin{tabular}{llll} 
Simulation name & Wind farms fleet or scenario & Nudging & Bias correction \\
\hline CTL & No wind farm & No nudging & No correction \\
CUR & End of 2012 Fleet & No nudging & No correction \\
SCEN & 2020 Fleet scenario & No nudging & No correction \\
NU-CTL & No wind farm & Upper-air spectral nudging & No correction \\
NU-SCEN & 2020 Fleet scenario & Upper-air spectral nudging & Bias correction \\
BC-SCEN & 2020 Fleet scenario & No nudging & No correction \\
CURa & $2011-2012$ Evolving & No nudging & No correction \\
CURb & $2011-2012$ Evolving fleet & Upper-air spectral nudging & Bias correction \\
BC-CURa & $2011-2012$ Evolving fleet & No nudging &
\end{tabular}

CTL, control; SCEN, scenario.

temperature difference amplitudes reach $\sim 0.3 \mathrm{~K}$, with scattered statistically significant positive values around the Baltic Sea $(P<0.05)$ and negative values over Southeast Europe (Fig. 2a). Winter precipitation (Fig. 2c) has a more patchy structure, but significant reduction was found over Western Europe reaching $0.15 \mathrm{~mm}$ per day, that is, $\sim 5 \%$ of mean precipitation. Sea-level pressure undergoes a maximal change of $0.5 \mathrm{hPa}$, reflecting an increased anticyclonic weather across Europe in winter (Fig. 2e). This anticyclonic signal is also present in the 500-hPa response with maximal amplitude of $5 \mathrm{~m}$ (not shown). It induces slight mean circulation changes, with more southerly flows over the western part of the domain and northerly flows over the eastern part, thus modifying heat and moisture advection. The winter temperature and precipitation responses however remains small compared with their respective interannual variability, reaching $\sim 10 \%$ for temperature and $20 \%$ for precipitation in some areas (Supplementary Fig. 6). In summer (Fig. 2b), responses are generally not significant (Fig. 2b,d,f); thus, hereafter we focus on the winter season.

Local and large-scale effects. Wintertime differences actually result from a combination of local effects in the areas densely covered with wind farms and large-scale effects due to the weak circulation changes described above. With increased southerlies over Westerrn Europe, more heat is advected over Scandinavia and increased northerlies bring a colder weather over Southeastern Europe. Atlantic weather systems are also slightly deflected northward, inducing less rainfall on continental Europe (Fig. 2c). The effect on temperature is enhanced when considering daily minimal temperatures as compared with maximal temperatures (Supplementary Fig. 7). In general, minimal temperatures occur at night after several hours of surface radiative cooling, inducing the formation of a cold, stable air layer near the ground with much warmer air aloft. Then, turbine-induced turbulence has a capacity to mix this layer with the upper air and significantly increase near ground temperature. In unstable afternoon conditions, air temperatures are fairly mixed near the ground due to thermal activity, in which case an additional turbulence source does not have such an effect. The local effect of wind turbines can be identified by performing a new pair of simulations where the upper air (above 2,500 m) winds are nudged to the ERA-Interim winds, both in the control (NU-CTL) and in the scenario (NU-SCEN), thereby inhibiting the turbines' effect on large-scale circulation (which we verified). In winter, the turbines induce a local warming (Fig. 3b), not exceeding $0.2 \mathrm{~K}$ in densely covered onshore areas, but 
a

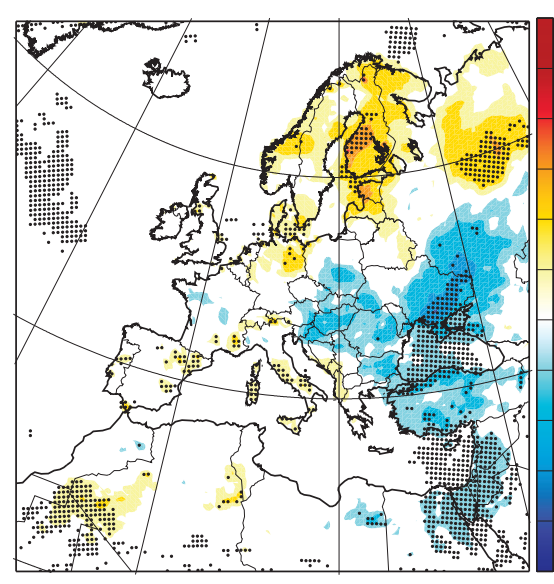

C

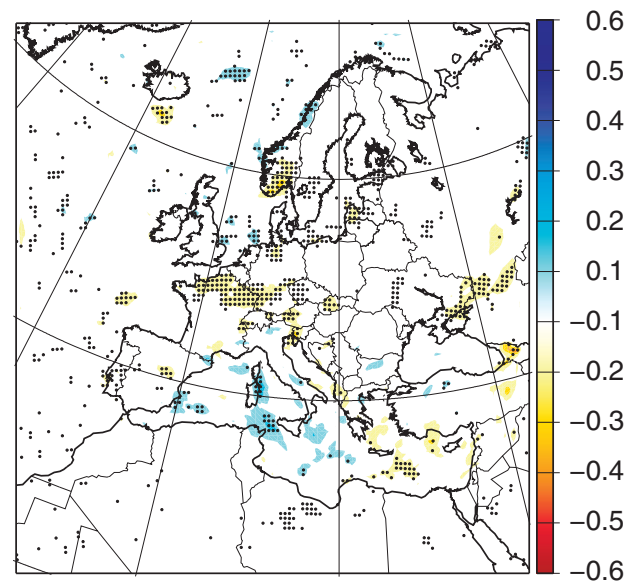

e

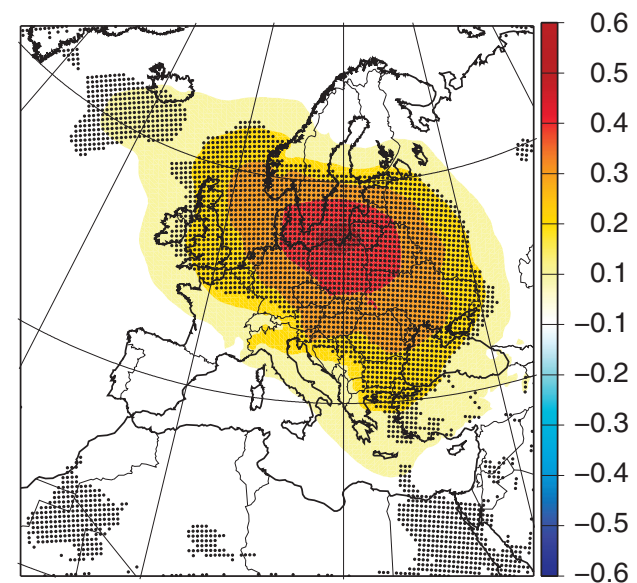

b

0.50
0.40
0.30
0.20
0.10
0.05
-0.05
-0.10
-0.20
-0.30
-0.40
-0.50

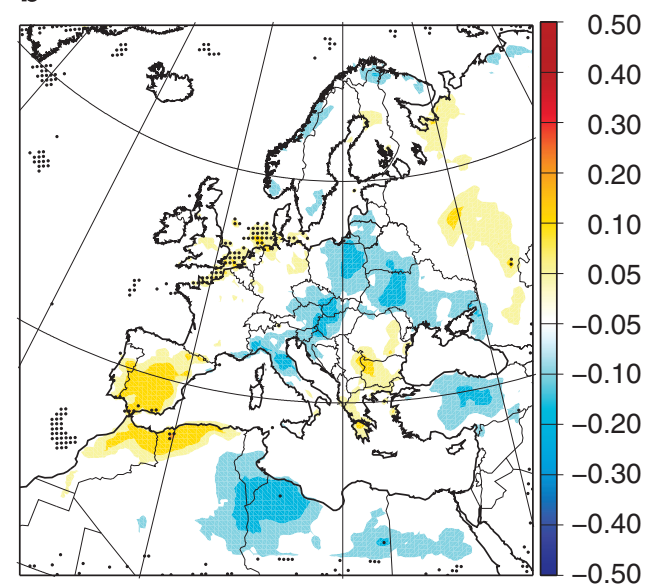

d

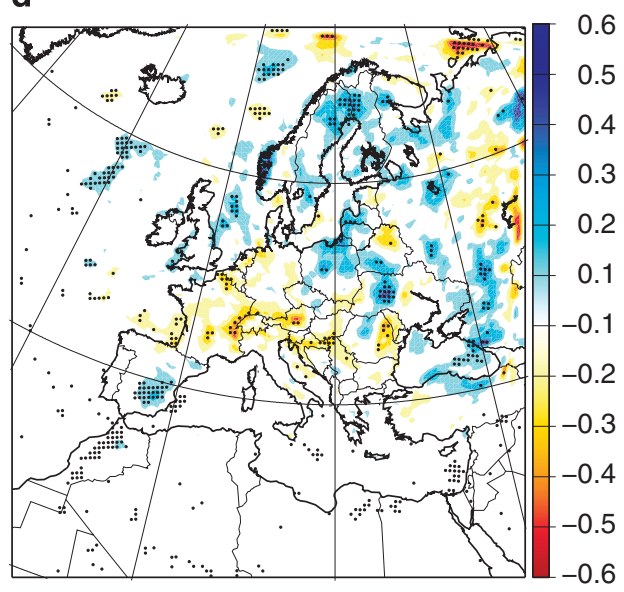

f

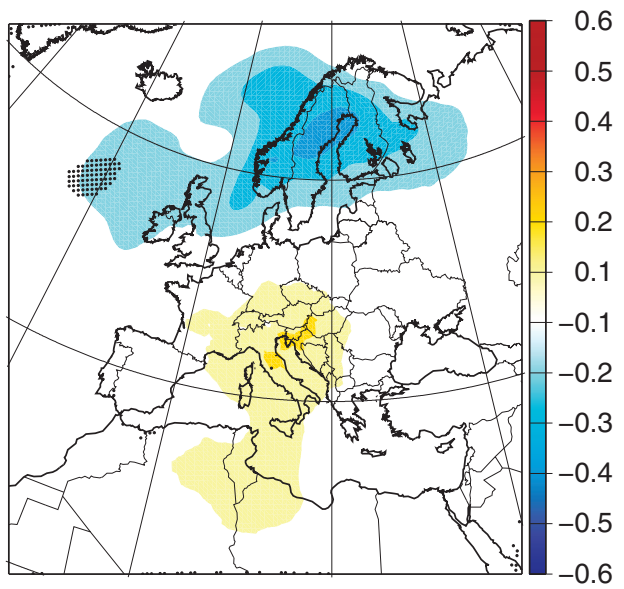

Figure 2 | Regional climate changes due to $\mathbf{2 0 2 0}$ installed wind power. Mean seasonal differences between the SCEN and the CTL simulations, for winter (left column) and summer (right column), for daily temperature (a,b, in K), precipitation (c,d, in mm per day) and sea level pressure (e,f, in hPa). Winter season is defined as the 3 months from December to February, and summer season from June to August. Regions with $95 \%$ confidence level of the differences (calculated as twice the s.d. of the 33 seasonal differences divided by the square root of the number of years) are highlighted with dots inside.

warming is not found in the Baltic Sea area. The in-land drying response to wind turbines is not found and, therefore, primarily results from the enhanced anticyclonic weather (compare Fig. 3c,d). The same conclusion holds for the 10-m wind decrease (compare Fig. 3e,f). The local impact of turbines has a small interannual variability, thus yielding statistically significant results in most areas when averaged over the 33 years in Fig. 3b,d,f (significance not shown for figure clarity).

Significant local onshore effects can be further quantified by averaging the differences between NU-SCEN and NU-CTL results over in-land grid cells with an installed capacity of $>0.55$ and $0.25 \mathrm{GW}$ respectively (Fig. 4). For reference, these two 
a

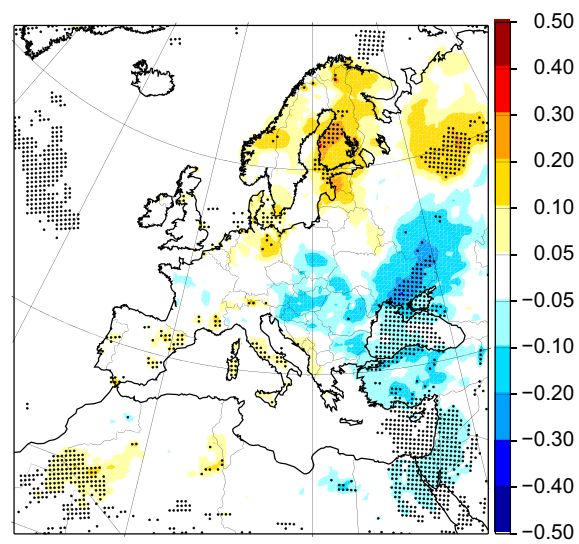

C

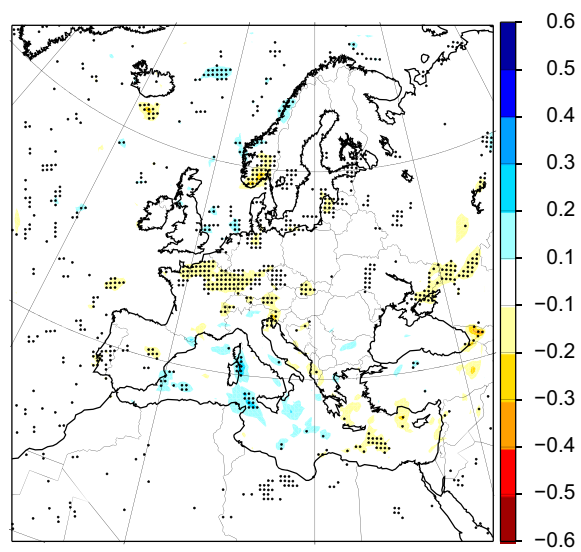

e

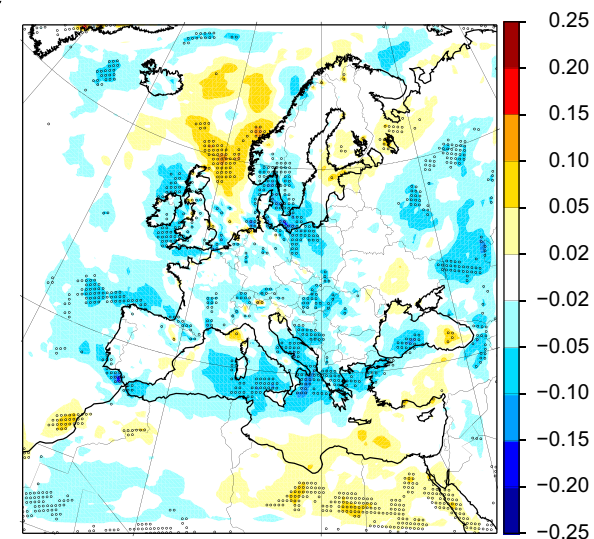

b

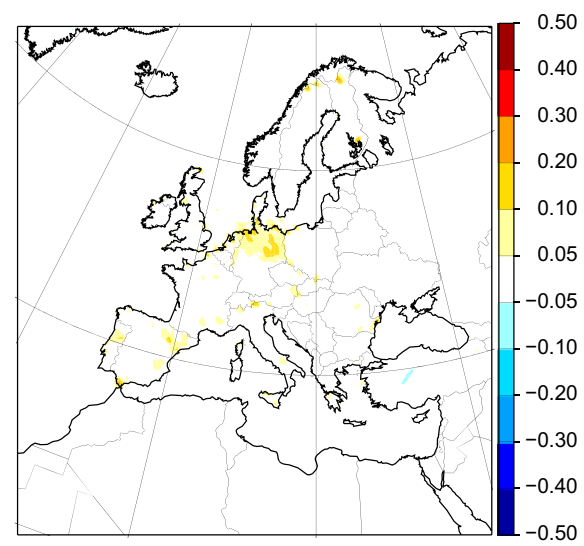

d

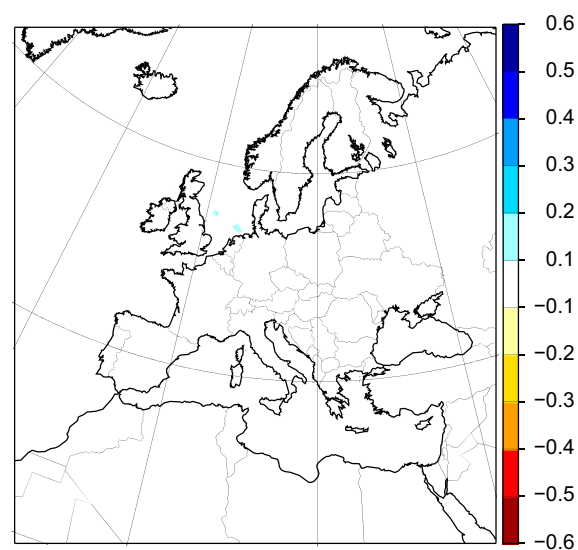

f

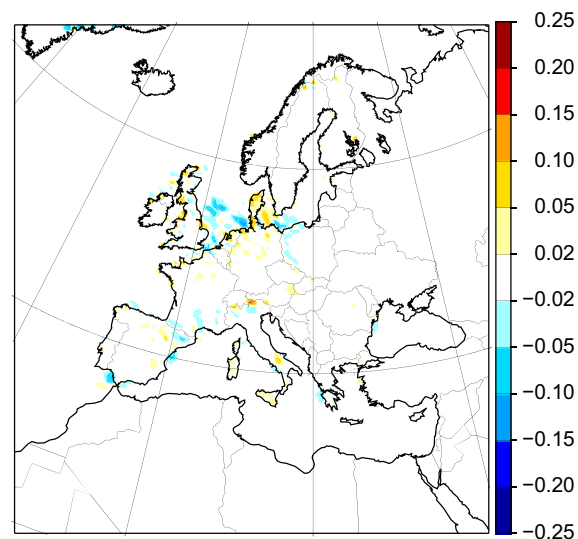

Figure 3 | Comparison of changes in nudged and non-nudged simulations. Mean winter-time (DJF) differences between the SCEN and the CTL simulations (left panels) and between NU-SCEN and CTL simulations (right panels), for daily temperature in K (a,b), precipitation in mm per day (c,d) and $10 \mathrm{~m}$ wind in $\mathrm{m} \mathrm{s}^{-1}(\mathbf{e}, \mathbf{f})$. Regions with 95\% confidence level of the differences (calculated as twice the s.d. of the 33 seasonal differences divided by the squared root of the number of years (33)) are highlighted with dots inside for the SCEN cases (a,c,e) but not for the NU-SCEN cases (b,d,f) for a better clarity of the figure. In these panels, all coloured areas with signal have statistical significance.

grid cell ensembles cover $\sim 50 \%$ of the 2020 and 2012 European onshore installed capacity, respectively. In Fig. 4, the local response is also averaged over all European in-land grid cells $(10 \mathrm{~W}-30 \mathrm{E} ; 35-75 \mathrm{~N})$ regardless of the installed capacity, to assess the overall local onshore effect over Europe (Fig. 4). Noticeable effects are found over densely covered areas, in particular for surface energy fluxes. In winter, turbines increase turbulence in stable boundary layers, reducing near-surface cold temperature layers and radiation fog. This increase of clear sky conditions induces a small increase in incoming shortwave radiation $\left(0.15 \mathrm{~W} \mathrm{~m}^{-2}\right)$ and a decrease in long-wave incoming radiation of $0.8 \mathrm{~W} \mathrm{~m}^{-2}$ on average. The additional turbulence induces a reduction of $1.2 \mathrm{~W} \mathrm{~m}^{-2}$ of sensible heat fluxes through an increase in top-down surface warming. It also increases latent heat fluxes by $\sim 0.4 \mathrm{~W} \mathrm{~m}^{-2}$. It also induces a mean warming of $0.1 \mathrm{~K}$, but as shown by Fig. 3 does not seem to induce noticeable precipitation effects.

Local and circulation change-driven effects are superimposed over densely covered areas, as it can be seen in Fig. 4 by comparing SCEN and NU-SCEN results, with sometimes opposite 
a

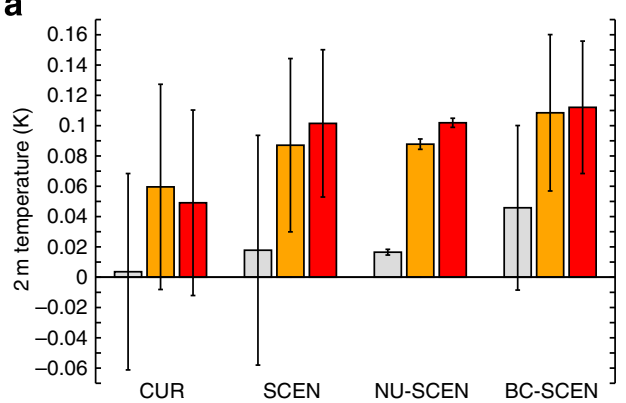

C

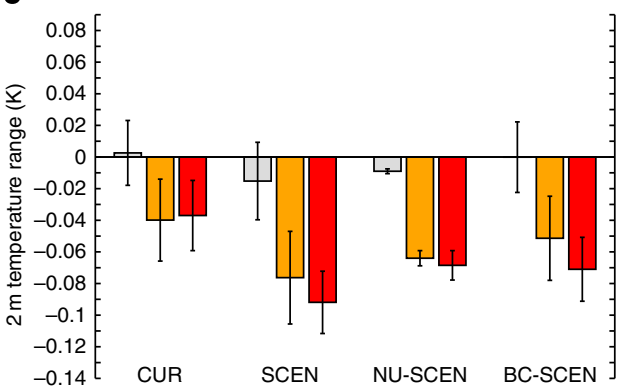

e

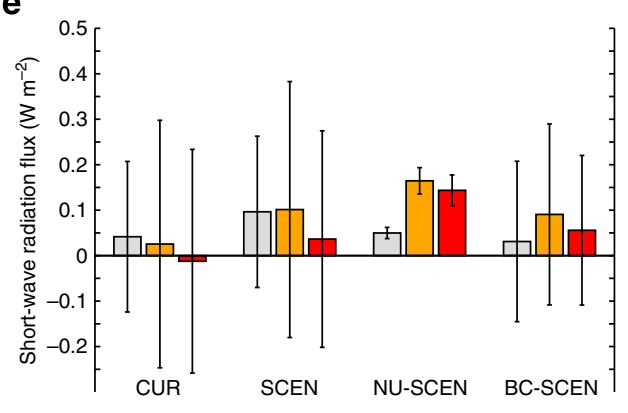

g

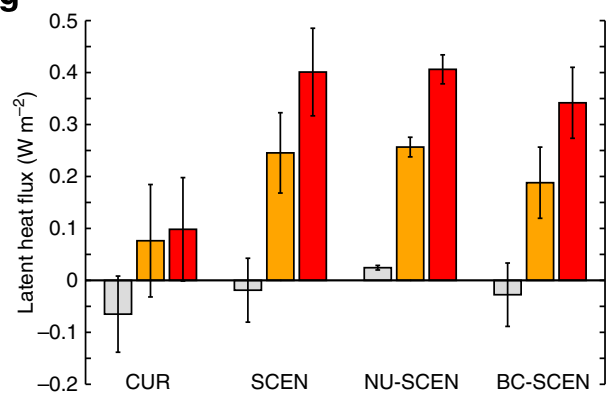

b

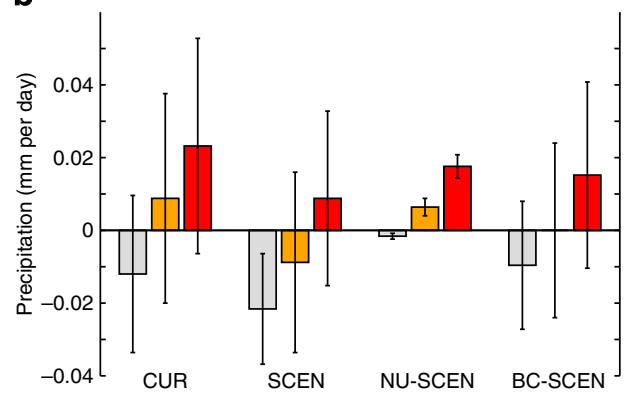

d

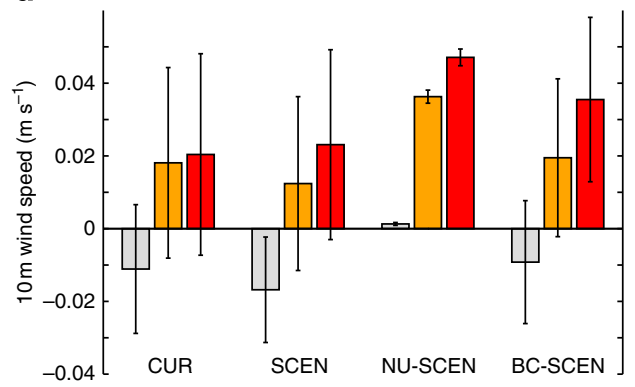

$f$

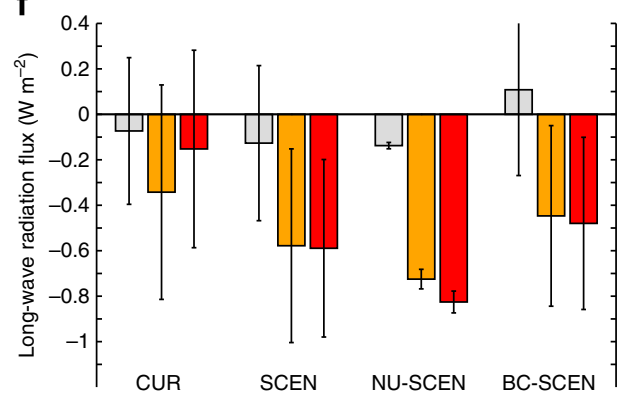

h

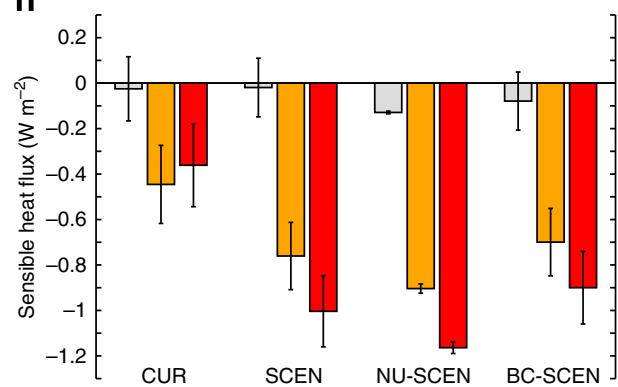

Figure 4 | Mean simulations differences over land. Differences, over several parameters, between the simulations with and without turbine for each season (from left to right series of bars for CUR-CTL, SCEN-CTL, NU-SCEN-NU-CTL, BC-SCEN-CTL), averaged over land areas of the full domain (grey bars), land grid cells with $>0.25 \mathrm{GW}$ of installed capacity (orange bars) and land grid cells with more than $0.55 \mathrm{GW}$ of installed capacity (red bars). 95\% Confidence intervals are calculated by first averaging each season over the concerned cells and taking the mean plus or minus twice the s.d. divided by the square root of the number of years of the resulting time series. (a) Temperature; (b) precipitation; (c) temperature range; (d) wind speed; (e) shortwave downwelling fluxes; (f) long-wave downwelling fluxes; (g) latent heat fluxes; (h) sensible heat fluxes.

signs. For instance, the enhanced anticyclonic weather induces a small but significant reduction in $10 \mathrm{~m}$ wind speed due to slight deflection of the mean westerly circulation northward. Local onshore turbine effects tend, on the contrary, to slightly increase surface winds, due to downward deflection of the flow below turbines ${ }^{8}$. The temperature range reduction is weaker in the SCEN than in the NU-SCEN case, also due to anticyclonic effects.

The effects of the current onshore wind turbines fleet (as of end of 2012) are similar to the effects of the 2020 fleet with reduced amplitude and statistical significance. This can be seen by comparing CUR and SCEN simulation results in Fig. 4 and in Supplementary Fig. 8. Only the 2020 fleet leads to statistically significant effects on circulation with the largest amplitude in winter.

\section{Discussion}

To estimate the effect of the wind speed bias on our results, a simple bias correction has been applied to the instantaneous 
wind speed profile before calculating the thrust and transfer of energy from momentum to wake turbulence at each time step of the model simulation in the 2020 scenario case (simulation BC-SCEN). This assumes a $20 \%$ reduction surface wind speed and a constant bias removal along the wind speed profile (see Methods for details). Results show an effect on temperature, its daily range and other variables, which remain within the uncertainty limits of the SCEN experiments (Fig. 4).

The climate effects for densely covered grid cell areas are generally smaller over offshore than over onshore areas (see Figs 2, 3 and Supplementary Fig. 8). This may be due to lower temperature gradients in the surface layer, reducing the effect of additional turbine-generated turbulence. However, a coupled ocean-atmosphere model that represents changes in sea surface temperature and surface current is required to properly study potential changes in offshore areas.

Our simulations show that local effects add up to the largescale circulation effects of wind farms. However, our simulations are carried out here at a low horizontal resolution of $50 \mathrm{~km}$. At this spatial scale, densely covered grid cells $(>0.55 \mathrm{GW})$ undergo a mean warming of $0.1 \mathrm{~K}$ together with decreases in sensible heat flux and increases in latent heat flux. Such capacity is in general not uniformly distributed inside the cells, and the impacts could therefore be larger in the vicinity of wind farms. This may explain the weaker local effects found in this study compared with previous studies of near-wind farm effects. To investigate this, a higher resolution is required. Limitations can also occur from the relatively coarse vertical resolution used here, as well as from model biases in stability. However, this last possibility is unlikely, as we could not find significant and systematic biases in the diurnal cycle of temperature over many areas in Europe (see Supplementary Fig. 9).

Another caveat of this study is the use of a limited-area model, possibly inhibiting deviations of the circulation at a much larger scale. However, results from an additional sensitivity simulation (not shown) where the domain was extended from the Eastern North American coast to the middle of Eurasia, roughly doubling the domain size, with a lower horizontal resolution $(100 \mathrm{~km})$ to limit computational cost, showed qualitatively similar results.

Larger changes can be expected in more intensive wind energy development policies such as indicated by the European Union roadmap 2050. In this horizon, fulfilling the target of a factor of 4 decrease of the greenhouse gases emissions, with respect to the 1990 level, will require to decarbonize the power sector significantly: the various technically feasible pathways lead to rates of renewable in the range $40-80 \%$ in the power sector against only $34 \%$ in a base line scenario. Wind power would play an important role, with onshore installed capacity up to $245 \mathrm{GW}$ and offshore up to $190 \mathrm{GW}$. These values would then roughly double the 2020 capacity. However, an extrapolation of our results to such more intensive scenarios is not possible here, and additional studies are needed to assess their impact on climate.

\footnotetext{
Methods

Observations used. Observations of wind speed at $10 \mathrm{~m}$ used to evaluate wind bias of the WRF system were taken from the ISD-LITE data base (http:// www.ncdc.noaa.gov/oa/climate/isd/index.php?name=isd-lite) and are taken over 99 sites from cup anemometer measurements. Preliminary to the evaluation, the same site selection and quality check as in a previous study ${ }^{30}$ was applied. Not to weigh the model evaluation over areas poorly covered with wind turbines, only sites in the area shown in Supplementary Fig. 1 are considered. Wind data were taken every $3 \mathrm{~h}$ to evaluate the model over the diurnal cycle. The ISD-LITE data set was also used for model temperature evaluation. However, the site-selection procedure was different, as our main aim is to evaluate the ability of the model to reproduce the diurnal cycle. Only European sites with $>90 \%$ of data between 1980 and 2012 are available for each hour. This left 206 sites for temperature evaluation.

The simulations used in this paper are evaluated against electricity production from wind farms. There is no agreed-on procedure to report wind-farm electricity
}

production in Europe. The information is not available for some countries. Some others report data for the previous week or month. The hourly production for the past few years is also available for a few countries. An important work of data collection and harmonization has been performed by Paul-Frederik Bach ${ }^{31}$. Wind electricity production with an hourly time step is made available for Denmark, Germany, Ireland, Great Britain, France and Spain. Only the totals are provided, with no description of the spatial structure of the production. These data have been used for the Supplementary Figs 4 and 5 .

WRF regional model configuration. Simulations used the WRF V3.3.1 model ${ }^{21}$ with parameterized turbine effects ${ }^{11}$. The configuration of WRF is almost similar to that used in the EURO-CORDEX experiment for the IPSL-INERIS simulations ${ }^{24,25}$ at the low resolution of $50 \mathrm{~km}$ over a rotated longitude-latitude grid. However, the planetary boundary laver scheme was changed to the Mellor-YamadaNakanishi-Niino scheme ${ }^{22}$, which includes the turbine effects, and we used here a different convection scheme ${ }^{32}$ because it was found over preliminary experiments to provide less-biased precipitation than the scheme used for the EURO-CORDEX experiments. Moreover, while keeping the same number of vertical level ${ }^{32}$, the vertical resolution was increased near the ground. The thickness of the first model layer is $\sim 20 \mathrm{~m}$, the second layer is $\sim 50 \mathrm{~m}$ deep and the third $\sim 80 \mathrm{~m}$ deep. Simulations started on 1 January 1979 and ended on 31 December 2012. They were forced at the boundaries by ERA-Interim re-analyses The full 1979 year was not considered in the analysis to remove any possible spinup effect in all experiments.

Wind turbine characteristics. The turbine representation requires, as input, several parameters for each wind turbine: turbine location, hub height, rotor diameter, nominal power, the thrust and power functions as a function of the wind speed. Individual turbine locations, nominal power and hub height were taken from the TheWindPower database (http://www.thewindpower.net), which collects all wind farm characteristics across the world. Farms for which nominal power was not present were rejected. Turbine diameter was estimated as a function of the nominal power on the basis of a collection of turbine information available from the same database. A reference nominal power of $2 \mathrm{MW}$ was assumed for each turbine when a farm total nominal power is available but not the number of turbines. The power curve for each turbine was not available, and it was approximated as a rather typical power curve of modern turbines by using the formulae

$$
\begin{gathered}
P(V)=0 \text { for } V \leq V_{\mathrm{i}}, \\
P(V)=P_{\mathrm{n}} \sin \left(\frac{\pi}{2}\left(V-V_{\mathrm{i}}\right) /\left(V-V_{\mathrm{n}}\right)\right)^{2} \text { for } V_{\mathrm{i}} \leq V \leq V_{\mathrm{n}}, \\
(V)=P_{\mathrm{n}} \text { for } V_{\mathrm{n}} \leq V \leq V_{\mathrm{o}}, \\
(V)=0 \text { for } V \geq V_{\mathrm{o}},
\end{gathered}
$$

where the cut-in speed $V_{\mathrm{i}}=3.5 \mathrm{~m} \mathrm{~s}^{-1}$, the cut-out speed $V_{\mathrm{o}}=25 \mathrm{~m} \mathrm{~s}^{-1}$ and $V_{\mathrm{n}}=15 \mathrm{~m} \mathrm{~s}^{-1}$, and the nominal power $P_{\mathrm{n}}$ depends on the turbine and is taken from the database. The power coefficient (ratio of extracted power to the wind power in the turbine 'tube') is then calculated from this curve and the turbine diameter, and is capped to 0.55 (Betz's law). The thrust coefficient (ratio of power transformed by the turbine, either to electrical or to TKE, to the available wind power) is assumed to be proportional to the power coefficient, $C_{\mathrm{T}}=1.75 C_{\mathrm{P}}$, with an upper limit value of 0.9. A standing minimal thrust coefficient of 0.157 was assumed. These assumptions are a simplification in the absence of accurate constructor data, which probably overestimates the thrust in high winds but underestimates in low winds (compare, for example, with ref. 15). An overestimation of thrust coefficient would be conservative for our conclusion that 2020 wind farm fleet should not induce noticeable climate perturbations. The power and thrust curves are displayed for instance on Supplementary Fig. 10, assuming a 2-MW and 80-m-diameter turbine. However, note that model wind farms have different characteristics and these curves actually stand as an example.

For the 2012 fleet simulations, we considered all functioning and commissioned at most 3 months before the end of 2012 year. For the 2020 scenario, we uniformly assumed both for onshore and offshore farms a nominal power of $2 \mathrm{MW}$ for each turbine.

The 2020 wind energy development scenario. The 2020 scenario used here follows the climate and energy package policy, which groups an ensemble of directives. This package was set up in late 2008 to decarbonize progressively the energy mix of Europe and move to the path of the 'factor 4' set by developed countries' 2050 goal of reducing gas emissions relative to 1990 . This intermediate frame for 2020 fixes three main objectives: $20 \%$ reduction in greenhouse gas emissions, a $20 \%$ improvement in energy efficiency compared with a scenario trend and a $20 \%$ renewable energy in final energy consumption $(14 \% \text { in } 2012)^{31}$. To achieve the latter goal, national targets have been differentiated to take into account country specificities, particularly the level of GDP. In the national renewable energy action plans ${ }^{23}$, member states had to notify European Commission their sectorial 
targets, technology mix, expected trajectory, measures and reforms undertaken to overcome barriers to developing renewable energy.

The 2020 scenario is based here on the available data from the database TheWindPower, providing the characteristics of wind farms onshore and offshore per country. We use only the specifications given for plants in operation, under construction or whose project is accepted (capacities, accurate localization and number of turbines per farm). For the other future projects, we consider the need of additional capacity for each country to meet its objectives (see Supplementary Table 1). These individual needs are divided in supposing an average power capacity turbine (2 MW for onshore). Although onshore projects are not included in the data base, a number of offshore projects were actually provided, and the scheduled capacity (of Supplementary Table 1) by the 2020 energy and climate package was actually below the capacity given by the database for offshore wind power.

The 2020 scenario is applied by assuming additional wind farms in areas where surface winds are strongest. A preliminary control simulation is carried out and surface winds are averaged. In the onshore case, the additional farms are placed progressively in grid cells with decreasing wind speeds, filling each grid cell with turbines until a limit of $1 \mathrm{GW}$.

Model wind speed evaluation and bias correction. To evaluate the model wind speeds, we used cup anemometer measurements gathered in the ISD-LITE database (see Methods). The comparison is made only on $10 \mathrm{~m}$ winds due to the lack of data at higher altitudes. A new simulation (CURa) of the model in the configuration as used in the CUR simulation was carried out over the years 2011 (starting on 1 January 2011) and 2012, and evaluated over the full year of 2012. However, as CURa was also used to evaluate energy production (see next section below), the growth of installed capacity along the 2 years was taken into account, by allowing individual wind farms in the model to be operational, in the model, 3 months after their commissioning date. This is not the case for the CUR simulations where the fleet is fixed to that of the end of 2012.

This simulation, which does not use nudging except at the domain boundaries, produces large-scale circulations that are not strictly following the actual circulation due to internal variability. To also examine the effect of constraining large-scale circulation while avoiding constraining surface winds, another 2-year simulation (CURb) was carried out using the spectral nudging technique for winds (only) above an altitude of $2,500 \mathrm{~m}$. In this case, one expects the model to represent each synoptic event and, therefore, the daily variations of large-scale circulationdriven winds while using the model surface and boundary layer physics.

Comparing $10 \mathrm{~m}$ wind biases of both simulations (CURa and CURb) is needed to ensure that these biases do not result from circulations internal to the domain, generated by the model, possibly generated by the turbines themselves in the model. This comparison then allows assessing the respective contributions of the simulated large-scale circulation biases and the boundary-layer physics shortcomings in the model $10 \mathrm{~m}$ wind bias.

We focused wind evaluation on regions relevant for wind energy. We calculated model $10 \mathrm{~m}$ wind bias over the area shown in Supplementary Fig. 1 (black square), which includes a high proportion $(\sim 50 \%)$ of the European turbine fleet. The quality-control test and a stringent selection of availability along the year 2012 (that is, stations for which data are available for $>15$ days with at least 5 measurements for each month of 2012) leave a total of 99 stations located within this area (see Supplementary Fig. 1). Both model surface wind diurnal and seasonal cycles are evaluated to identify any diurnal or seasonal bias dependency. Supplementary Fig. 2 shows that for both simulations (CURa, CURb), the model overestimates $10 \mathrm{~m}$ wind speed by $\sim 20 \%$ compared with ISD-LITE observed winds, whatever the time of day and year. A comparison between quantiles of the observed and simulated $10 \mathrm{~m}$ wind distributions also shows that for most of the wind regimes of the distribution, the wind overestimation does not strongly differ from a $20 \%$ overestimation (Supplementary Fig. 3) for the range relevant for turbine functioning, that is, within the cut-in speed $\left(3.5 \mathrm{~m} \mathrm{~s}^{-1}\right)$ and cut-out speed $\left(25 \mathrm{~m} \mathrm{~s}^{-1}\right)$. This calls for a simple bias correction choice such as a constant $20 \%$ reduction applied to model wind, which appears coarse but reasonable, as the aim here is mainly a sensitivity experiment (see here below).

The fact that the CURa mean bias is only sligthly stronger than the CURb shows that model wind bias is not driven by deficiency in the simulated large-scale circulation but is rather related to the boundary-layer and surface physics formulation in the model. This also ensures the relevance of the turbine effect comparison between SCEN and NU-SCEN.

It is noteworthy that as model wind evaluation is carried out using simulations with turbine parameterization coupled to the boundary layer, one may question the role of this coupling in the detected model wind bias. However, Fig. 3 (in the article main body) shows that the turbine effects on $10 \mathrm{~m}$ wind $\left(\sim 0.1 \mathrm{~m} \mathrm{~s}^{-1}\right)$ is an order of magnitude smaller than the model wind bias, which indicates that this bias is not due to wind farms.

Wind bias correction. To account for the model wind bias, we also carried out a sensitivity simulation (BC-SCEN) using a simplified online bias correction at each time step, to calculate power output and thrust. At each level where wind speed was used for the turbines in the model, the wind velocity used to calculate turbine effects for TKE input, momentum extraction and power was corrected by removing a constant velocity (in the absence of bias information along the profile) equal to $20 \%$ of the wind speed at the first model level. This correction and the BC-SCEN simulation should be considered as a sensitivity experiment. More physically based approaches should directly correct the roughness in the model, taking into account, for instance, the unresolved orography ${ }^{27}$ to increase model realism. To assess the ability of the model to simulate the power output using this correction, another 2011-2012 simulation (BC-CURa) was carried out with the varying turbine fleet as above and the bias correction (see below).

Energy output evaluation. The electrical power outputs from CURa, CURb and the bias-corrected BC-CURa sensitivity experiments were calculated over the year 2012 and compared with the reported electrical power from production networks collected and made available from ref. 31. Even though mean power for each country is significantly overestimated (see Supplementary Table 2), the hourly variability of production is well simulated in the CURb case where upper-air spectral nudging is applied (Supplementary Fig. 4). In this case, simulated outputs have correlation coefficients in the order of 0.9 . For the other simulations (CURa and $\mathrm{BC}-\mathrm{CURa}$ ), poorer correlations are expected due to internal variability within the model domain.

The fact that BC-CURa simulation still overestimates power output significantly for Germany, France, Ireland and the United Kingdom remains to be explained. Possible reasons are suboptimal functioning mentioned in the article main body, but also model regional variation in biases not considered here.

Diurnal cycle and a 30-day moving average for simulated and observed data are shown in Supplementary Fig. 5, after normalizing outputs by the annual average. All simulations capture the main variability across the seasonal and diurnal cycles, with a fair reproduction of time patterns for the nudged simulation.

\section{References}

1. Pierrot, M. The Wind Power, http://www.thewindpower.net (2013).

2. Pryor, S. C. \& Barthelmie, R. J. Assessing climate change impacts on the near-term stability of the wind energy resource over the United States. Proc. Natl Acad. Sci. USA 108, 8167-8171 (2012).

3. Michelangeli, P.-A., Vrac, M. \& Loukos, H. Probabilistic downscaling approaches: 'Application to wind cumulative distribution functions'. Geophys. Res. Lett. 36, L11708 (2009).

4. Hueging, H., Haas, R., Born, K., Jacob, D. \& Pinto, J. G. Regional changes in wind energy potential over Europe using regional climate model ensemble projections. J. Appl. Meteorol. Climatol. 52, 903-917 (2013).

5. Roy, S. B. \& Traiteur, J. J. Impacts of wind farms on surface air temperatures. Proc. Natl Acad. Sci. USA 107, 17899-17904 (2010).

6. Zhou, L. et al. Impacts of wind farms on land surface temperature. Nat. Clim. Chang. 2, 539-543 (2012).

7. Zhou, L. et al. Diurnal and seasonal variations of wind farm impacts on land surface temperature over Western Texas. Clim. Dynam. 41, 307-326 (2013).

8. Rajewski, D. A. et al. Crop Wind Energy Experiment - Observations of surface layer, boundary layer, and mesoscale interactions with a wind farm. Bull. Amer. Meteor. Soc. 94, 655-672 (2013).

9. Roy, S. B. Simulating impacts of wind farms on local hydrometeorology. J. Wind Eng. Industrial Aerodyn. 99, 491-498 (2011).

10. Roy, S. B., Pacala, S. W. \& Walko, R. L. Can large wind farms affect local meteorology? J. Geophys. Res. 109, D19101 (2004).

11. Zhang, W., Markfort, C. D. \& Porté-Agel, F. Experimental study of the impact of large-scale wind farms on land-atmosphere exchanges. Environ. Res. Lett. 8 , 015002 (2013).

12. Fitch, A. C. et al. Local and mesoscale impacts of wind farms as parameterized in mesoscale NWP model. Mon. Weather Rev. 140, 3017-3038 (2012).

13. Smith, C. M. et al. In situ observations of the influence of a large onshore wind farm on near-surface temperature, turbulence intensity and wind speed profiles. Environ. Res. Lett. 8, 034006 (2013).

14. Miller, L. M., Gans, F. \& Kleidon, A. 2011: Estimating maximum global land surface wind power extractability and associated climatic consequences. Earth Syst. Dyn. 2, 1-12 (2011).

15. Adams, A. S. \& Keith, D. W. Are global wind power resource estimates overstated? Environ. Res. Lett. 8, 015021 (2013).

16. Barrie, D. B. \& Kirk-Davidoff, D. B. Weather response to a large wind turbine array. Atmos. Chem. Phys. 10, 769-775 (2010).

17. Keith, D. et al. The influence of large-scale wind power on global climate. Proc. Natl Acad. Sci. USA 101, 16115-16120 (2004).

18. Fiedler, B. H. \& Bukowsky, M. S. The effect of a giant wind farm on precipitation in a regional climate model. Environ. Res. Lett. 6, 045101 (2011).

19. Wang, C. \& Prinn, R. G. Potential climatic impacts and reliability of very large-scale wind farms. Atmos. Chem. Phys. 10, 2053-2061 (2010).

20. Fitch, A. C., Olson, J. B. \& Lundquist, J. K. Parameterization of wind farms in climate models. J. Climate 26, 6439-6458 (2013).

21. Skamarock, W. C. et al. A description of the Advanced Research WRF version 3. NCAR Tech. Note 1-125 (2008). 
22. Nakanishi, M. \& Niino, H. Development of an improved turbulence closure model for the atmospheric boundary layer. J. Meteor. Soc. Jpn 87, 895-912 (2009).

23. European Commission. Energy, Action Plans and Forecasts, http://ec.europa.eu/ energy/renewables/action_plan_en.htm (2013).

24. Vautard, R. et al. The simulation of European heat waves from an ensemble of 1 regional climate models within the EURO-CORDEX project. Clim. Dynam. 41, 2555-2575 (2013).

25. Jacob et al. EURO-CORDEX: New high-resolution climate change projections for European impact research. Regional Environ. Change doi:10.1007/s10113-0130499-2 (2013)

26. Miglietta, M. et al. Evaluation of WRF model performance in different European regions with the DELTA-FAIRMODE evaluation tool. Int. J. Environ. Pollution 50 Nos. 1/2/3/4, 2012 83-97 (2012).

27. Jimenez, P. A. \& Dudhia, J. Improving the representation of resolved and unresolved topographic effects on surface wind in the WRF model. J. Appl. Meteorol. Climatol. 51, 300-316 (2012).

28. Liu, P. et al. Differences between downscaling with spectral and grid nudging using WRF. Atmos. Chem. Phys. 12, 3601-3610 (2012).

29. Hansen, K. S., Barthelmie, R. J., Jensen, L. E. \& Sommer, A. The impact of turbulence intensity and atmospheric stability on power deficits due to wind turbine wakes at Horns Rev wind farm. Wind Energy 15, 183196 (2012).

30. Vautard, R., Cattiaux, J., Yiou, P., Thepaut, J.-N. \& Ciais, P. Northern hemisphere atmospheric stilling partly attributed to an increase in surface roughness. Nat. Geosci. 3, 756-761 (2010).

31. Bach, P. F. \& Bach, Paul-Frederik. http://pfbach.dk (2013).

32. Kain, J. S. \& Fritsch, J. M. Convective parameterization for mesoscale models: The Kain-Fritsch scheme. The representation of cumulus convection in numerical models. Meteor. Monogr., Amer. Meteor. Soc. 24, 165-170 (1993).

\section{Acknowledgements}

All simulations have been carried out on the CCRT-TGCC supercomputer centre. The evaluation framework of the model wind speeds, together with the application of the wind power generation calculations over the European fleet were supported partly within the FP7 IMPACT2C project (grant FP7-ENV.2011.1.1.6-1) and the Commissariat à l'Energie Atomique et aux Energies Alternatives (CEA/DSM) internal research programme on energy. We are thankful to T. Peterson who provided us access to the ISDLITE data base, and to P.F. Back for collecting, formatting and making accessible the wind production data.

\section{Author contributions}

R.V. designed the experiments with his team and carried out the simulations. F.T. participated in the experimental designing and designed the 2020 wind energy scenario. I.T. carried out the evaluation of the model wind. F.-M.B. collected the wind energyoutput data and carried out the evaluation of simulated power outputs. J.-G.D.d.L., P.Y. and P.M.R. participated in designing of the experiments and the interpretation of results. A.C. contributed to the modelling chain construction. All authors participated to the article writing.

\section{Additional information}

Supplementary Information accompanies this paper at http://www.nature.com/nature communications

Competing financial interests: The authors declare no competing financial interests.

Reprints and permission information is available online at http://npg.nature.com/ reprintsandpermissions/

How to cite this article: Vautard, R. et al. Regional climate model simulations indicate limited climatic impacts by operational and planned European wind farms. Nat. Commun. 5:3196 doi: 10.1038/ncomms4196 (2014). 